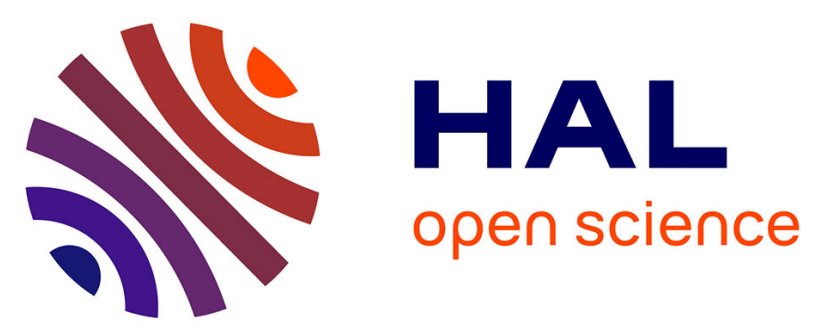

\title{
Three-Dimensional Reconstruction of Foot in the Weightbearing Position From Biplanar Radiographs: Evaluation of Accuracy and Reliability
}

Pierre-Yves Rohan, Antoine Perrier, Mira Ramanoudjame, Jérôme Hausselle, Henri Lelièvre, Raphael Seringe, Wafa Skalli, Philippe Wicart

\section{To cite this version:}

Pierre-Yves Rohan, Antoine Perrier, Mira Ramanoudjame, Jérôme Hausselle, Henri Lelièvre, et al.. Three-Dimensional Reconstruction of Foot in the Weightbearing Position From Biplanar Radiographs: Evaluation of Accuracy and Reliability. Journal of Foot and Ankle Surgery, 2018, 57 (5), pp.931-937. 10.1053/j.jfas.2018.03.014 . hal-02305618

\section{HAL Id: hal-02305618 https://hal.science/hal-02305618}

Submitted on 4 Oct 2019

HAL is a multi-disciplinary open access archive for the deposit and dissemination of scientific research documents, whether they are published or not. The documents may come from teaching and research institutions in France or abroad, or from public or private research centers.
L'archive ouverte pluridisciplinaire HAL, est destinée au dépôt et à la diffusion de documents scientifiques de niveau recherche, publiés ou non, émanant des établissements d'enseignement et de recherche français ou étrangers, des laboratoires publics ou privés. 


\title{
Three-Dimensional Reconstruction of Foot in the Weightbearing Position From Biplanar Radiographs: Evaluation of Accuracy and Reliability
}

\author{
Pierre-Yves Rohan, $\mathrm{PhD}^{1}$, Antoine Perrier, $\mathrm{PhD}^{2}$, Mira Ramanoudjame, $\mathrm{MD}^{3}$, Jérôme Hausselle, $\mathrm{PhD}^{1,4}$, \\ Henri Lelièvre, $\mathrm{MD}^{3}$, Raphael Seringe, $\mathrm{MD}^{5}$, Wafa Skalli, $\mathrm{PhD}^{6}$, Philippe Wicart, MD, $\mathrm{PhD}^{5}$
}

\author{
${ }^{1}$ Assistant Professor, Institut de Biomécanique Humaine Georges Charpak, Arts et Métiers ParisTech, Paris, France \\ ${ }^{2}$ Podiatrist, Institut de Biomécanique Humaine Georges Charpak, Arts et Métiers ParisTech, Paris, France \\ ${ }^{3}$ Orthopaedic Surgeon, Institut de Biomécanique Humaine Georges Charpak, Arts et Métiers ParisTech, Paris, France \\ ${ }^{4}$ Assistant Professor, BAMM Laboratory, Mechanical Aerospace and Engineering, Oklahoma State University Stillwater, Stillwater, OK \\ ${ }^{5}$ Orthopaedic Surgeon, Hôpital Necker-Enfants-Malades, Université Paris Descartes, AP-HP, Paris, France \\ ${ }^{6}$ Professor, Institut de Biomécanique Humaine Georges Charpak, Arts et Métiers ParisTech, Paris, France
}

\section{A R T I C L E I N F O}

Level of Clinical Evidence: 5

Keywords:

3D modeling

biplanar radiographs

clinical 3D measurements

foot

weightbearing

\section{A B S T R A C T}

The initial assessment and postoperative monitoring of patients with various abnormalities of the foot in clinical routine practice is primarily based on the analysis of radiographs taken in the weightbearing position. Conventional x-ray imaging, however, only provides a 2-dimensional projection of 3-dimensional (3D) bony structures, and the clinical parameters assessed from these images can be affected by projec-tion biases. In the present work, we addressed this issue by proposing an accurate 3D reconstruction method of the foot in the weightbearing position from low-dose biplanar radiographs with clinical index measurement assessment for clinical routine practice. The accuracy of the proposed reconstruction method was evaluated for both shape and clinical indexes by comparing 3D reconstructions of 6 cadaveric adult feet from computed tomographic images and from biplanar radiographs. For the reproducibility study, 3D reconstructions from the biplanar radiographs of the foot of 6 able-bodied subjects were consid-ered, with 2 observers repeating each measurement of anatomic landmarks 3 times. Baseline assessment of important 3D clinical parameters was performed on 17 subjects (34 feet; mean age 27.7, range 20 to 52 years). The average point to surface distance between the 3D stereoradiographic reconstruction and the computed tomographic scan-based reconstruction was $1 \mathrm{~mm}$ (range $0 \mathrm{~mm}$ to $6 \mathrm{~mm}$ ). The selected ra-diographic landmarks were highly reproducible $(95 \%$ confidence interval $<2.0 \mathrm{~mm})$. The greatest interindividual variability for the clinical parameters was observed for the twisting angle (mean $87^{\circ}$, range $73^{\circ}$ to $100^{\circ}$ ). Such an approach opens the way for routine 3D quantitative analysis of the foot in the weightbearing position.

The diagnosis and clinical treatment of patients with foot and ankle abnormalities is primarily based on the analysis of radiographs taken in the weightbearing position. The accurate understanding of the bony alignment on anteroposterior (AP) and lateral weightbearing radio-

Financial Disclosure: This work was supported by the PArisTech BiomecAM chair program on subject-specific musculoskeletal modeling, in particular, COVEA and Société Générale.

Conflict of Interest: W.S. is co-inventor of the EOS system without any personal financial benefit.

Address correspondence to: Pierre-Yves Rohan, PhD, Institut de Biomécanique Humaine Georges Charpak, Arts et Métiers ParisTech, 151 Boulevard de l'Hôpital, Paris 75013, France.

E-mail address: pierre-yves.rohan@ensam.eu (P-Y. Rohan). graphs, in particular, is paramount for the initial assessment, preoperative planning, and postoperative monitoring of patients $(1,2)$. Conventional x-ray imaging, however, suffers from limitations regarding magnification errors, image distortion, and the lack of 3-dimensional (3D) information (2-4). Moreover, the clinical parameters assessed from these images can be affected by projection biases that can alter the clinical decision-making process (5).

Computed tomography $(\mathrm{CT})$ and magnetic resonance imaging allow for 3D imaging of the foot and are considered superior in evaluating various bone pathologies (6-8). They both, however, require a quite lengthy 3D reconstruction process, and the scanners used in clinical routine practice are limited to the supine position (9). Furthermore, CT scanning exposes the patient to a high level of radiation, making 
their use limited in routine practice (10). Recent development in weightbearing CT scanning (11) has allowed imaging the foot and ankle under a natural loading condition, paramount for the assessment of osteoarticular architectural parameters $(1,12)$. However, weightbearing CT scans are not widespread in clinical routine practice, and, owing to the limited field of imaging ( $20 \mathrm{~cm}$ from the floor), the analysis of the complete lower limb cannot be performed.

Recent developments in 3D reconstruction techniques from calibrated biplanar x-ray imaging $(13,14)$ have provided tools for patientspecific 3D modeling of the spine (15), rib cage (16-18), upper limb (19), lower limb $(4,20)$, and external envelope (21). Most of these developments have been implemented in the EOS biplanar imaging system (EOS Imaging, Paris, France) and associated STEREOS software, allowing for routine 3D investigations. Sutter et al (5) also reported a hindfoot alignment measurement technique using lowdose biplanar radiographs and showed that 3D hindfoot alignment measurements based on biplanar radiographs were substantially better than measuring the hindfoot alignment on long-axial view radiographs, improving both the initial evaluation and the planning of therapy. Biplanar x-ray imaging, therefore, appears to be a reasonable method for evaluation of foot and ankle deformities and opens the way for the evaluation of important clinical 3D indexes. This could potentially help to address phenomena that cannot be clinically quantified such as the twisting of the lamina pedis described by MacConnail et al (22) (measured as a twisting angle), an issue of major interest for physiopathologic analysis of feet deformities and, in particular, cavus and flat feet (3).

The aim of the present study was to propose and validate a new method for $3 \mathrm{D}$ reconstruction of the foot and ankle in the weightbearing position from low-dose biplanar radiographs with clinical measurement assessment for clinical routine practice. Special attention was given to the foot twisting angle.

\section{Materials and Methods}

\section{Data Collection}

After approval by the ethical committee (Advisory Committee for the Protection of Individuals in Biomedical Research protocol no. 06036) and written informed consent,
17 asymptomatic adult volunteers ( 9 females, 8 males; age range 20 to 52 years) were included in the present study.

For the in vitro shape accuracy evaluation, 6 fresh-frozen cadaveric feet were imaged using a standard clinical CT scan protocol of $0.6-\mathrm{mm}$ slice thickness and reconstructed using the AVIZO software (Visualization Sciences Group, Bordeaux, France).

\section{Radiographic Acquisition Protocol}

Biplanar radiographs were taken from the pelvis to toe in frontal and sagittal views using the EOS low-dose imaging device (BiospaceMed, Paris, France). Because of the lack of anatomic landmark visibility in the foot on radiographs, 2 positions were considered. First, the volunteers were positioned in the standard "shifted-feet" standing position (Fig. 1A) as described by Chaibi et al (4). In this position, the right foot was shifted forward until the left foot anterior extremity was level with the first metatarsophalangeal joint of the right foot. Next, for the second acquisition, the subjects were instructed to incline the weightbearing foot by $\sim 10^{\circ}$ in the sagittal plane by placing the heel on a 20 -mm-high x-ray transparent plate (Fig. $1 B-D$ ). This allowed us to increase the visibility of the bones in the frontal radiographs. The subjects were also instructed to put the non-weightbearing foot on tip toe to avoid overlapping with the left foot. We termed this second position the "monopodal and contralateral equine unloaded foot position."

In total, 3 pairs of radiographs were acquired, 1 in the free standing position, 1 with the right foot in the equine position, and 1 with the left foot in the equine position. The pair of radiographs with the right foot in the loaded position and contralateral in the equine unloaded position was used to define the 3D model of the right foot and vice versa.

\section{Image Reconstruction}

The phalanges were not considered in the present study, and the foot was modeled as the union of the 7 tarsal bones (calcaneus, talus, medial intermediate and lateral cuneiforms, cuboid, and navicular) and the 5 metatarsal bones. A rigid "scaphoid group" composed of the cuneiforms, navicular, and second and third metatarsal bones was defined owing to the negligible motion between these bones.

The developed method for 3D reconstruction of the foot from low-dose biplanar radiographs was adapted from that proposed by Chaibi et al (4). The method is based on the definition of 2 models:

1. A 3D simplified personalized parametric model (SPPM) was defined by representing the main features of each bone by geometric primitives (i.e., 3D points, spheres, cylinders, and 3D segments). For our study, a collection of 27 geometric primitives defined on both the face and profile radiographs of 1 of the monopodal and contralateral equine unload foot position images were used (Fig. 2A). These have been summarized in Table 1 .

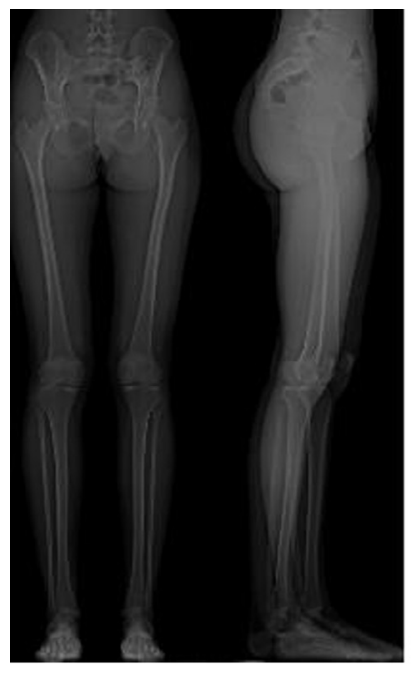

(A)

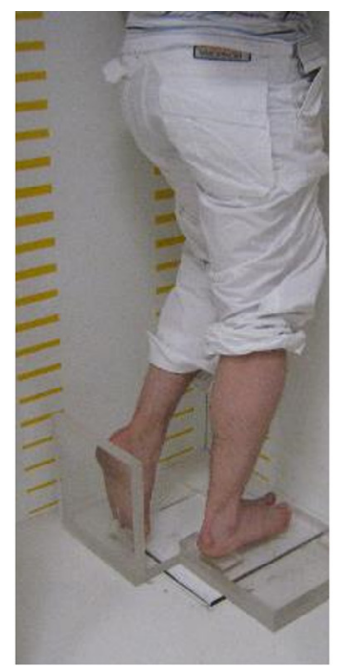

(B)

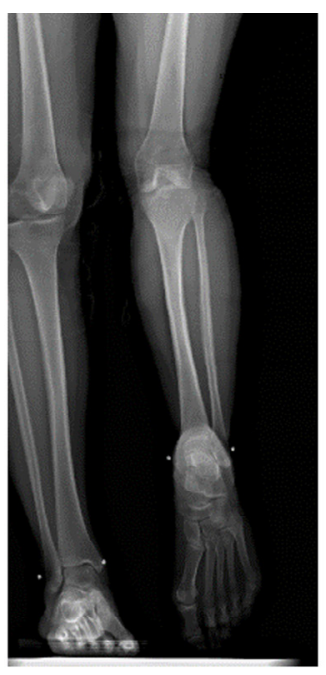

(C)

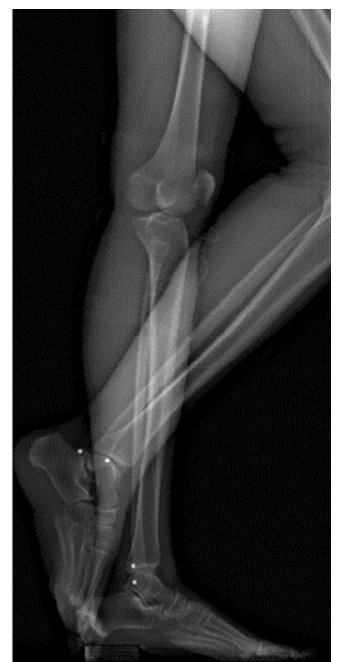

(D)

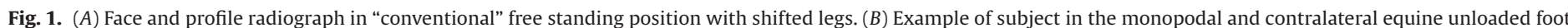
position, $(C)$ face radiograph, and $(D)$ profile radiograph. 

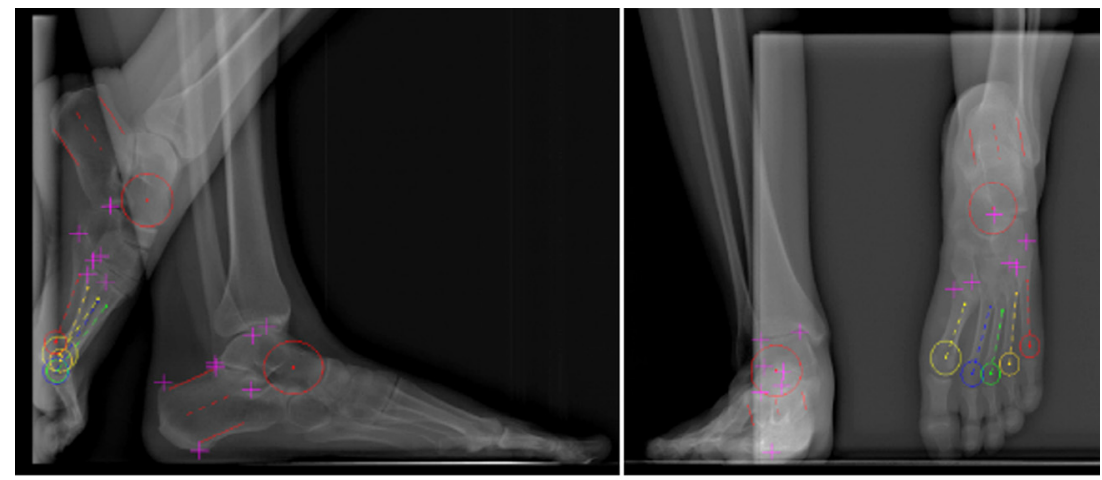

(A)

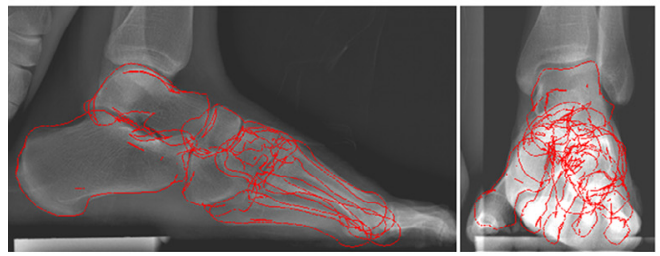

(B)

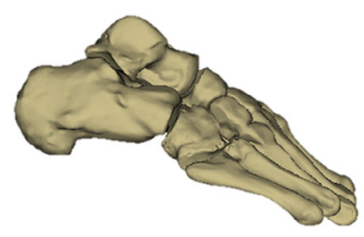

(C)

Fig. 2. Three-dimensional reconstruction of the foot from biplanar radiographs: (A) Geometric primitives of the simplified personalized parametric model on the face and profile radiographs. The descriptive parameters placed on the anatomic landmarks to represent the main features of each bone are described in Table 2. (B) Retroprojection of the deformed morpho-realistic personalized parametric model of the weightbearing foot after adjustment. (C) Three-dimensional reconstruction of the foot.

2. A morpho-realistic personalized parametric model (MPPM; generic, triangular surface mesh) was defined from the 3D reconstruction of a CT scan. We used a postmortem asymptomatic cadaver CT scan (i.e., without any history of traumatic or congenital disorders, characteristic deformation, or arthrosis, synostosis, or supernumerary bone). This model was regionalized and parameterized in coherence with the SPPM. The features of the SPPM could then be used to drive the 3D deformation of the MPPM to obtain a morpho-realistic representation of the foot (Fig. 2B,C).

The 3D foot reconstruction method was performed in 3 steps using custom-made software developed by the Institut de Biomecanique Humaine Georges Charpak (Arts et Métiers ParisTech, Paris, France):

1. The process began with placement of the anatomic landmarks and geometric primitives on the face and profile radiographs of 1 of the monopodal and contralateral equine unload foot position configurations. More precisely, the anatomic landmarks calcaneus (C)1, C2, C3, C6, talus (T)2, T3, and T4 were manually positioned on the loaded foot, and cuboid (CU)2, CU3, metatarsal (M)52, M53, M12, and M15 were manually positioned on the unloaded foot. The elliptical cylinders of both the calcaneus and talus and the sphere of the talus were positioned on the loaded foot, and the elliptical cylinders of the calcaneus and spheres of the talus, M2, M3, M4 and M5 were positioned on the unloaded foot. Next, using a hypothesis of symmetry, the data from the unloaded foot were merged with those of the loaded foot. This defined a SPPM (Fig. 2A).

2. The SPPM was then used to deform the generic 3D MPPM using both a moving least squares algorithm (23) and the kriging method (24). The moving least squares algorithm was used to perform an "as-rigid-as-possible" deformation of the template model, and the kriging method was used to control local deformations.

3. This initial solution was then projected on the face and profile radiographs, and manual adjustments were performed by the operator to improve the superposition between the projected contours and the actual ones on the radiographs (Fig. 2B,C).

Method Evaluation

Accuracy Assessment

The accuracy of the proposed 3D reconstruction method was assessed in vitro on 6 cadaveric adult feet by 1 operator. CT and biplanar x-ray imaging (monopodal and contralateral equine unloaded foot position) of each cadaver specimen were first performed. The CT scan was reconstructed once using the AVIZO software (Visualization Sciences Group) and compared with the corresponding stereoradiographic reconstruc- tion. The comparison of both reconstructions was performed by calculating the pointto-surface distance between the CT scan reconstruction and the 3D stereoradiographic reconstruction. The mean error, 2 root mean square (RMS) error, and maximum error were computed.

\section{Reliability Assessment}

For the reliability analysis, each pair of radiographs ( 6 subjects) was reconstructed 3 times by 2 qualified operators. The interval between the 2 consecutive reconstructions by 1 operator was a minimum of 1 day. The standard deviations of reproducibility of the anatomic landmarks were computed according to the International Organization for Standardization 5725 standard. The reliability was then estimated considering the $95 \%$ confidence interval $(\mathrm{CI})$ as $2 \times$ the standard deviations of reproducibility.

\section{Baseline for Clinical Indexes}

Baseline assessment of the clinical parameters was performed on 17 asymptomatic adult volunteers. The clinical parameters that were computed from the SPPM have been summarized in Table 2. In addition to the main indexes used in clinical routine practice (25) to describe the foot morphologic types, we also considered the twisting angle, defined as the angle between 2 planes (the sagittal plane of the calcaneus and the plane involving the first metatarsal axis and the center of the fifth metatarsal head; Fig. 3). To facilitate the comparison with the reported data, some of the 3D angles were projected in the AP and lateral planes.

\section{Statistical Analysis}

The baseline data for clinical indexes were checked for normality using the Kolmogorov-Smirnov test and, where applicable, the mean \pm standard deviation are reported. Statistical significance was defined at the $5 \%(p \leq .05)$ level. A paired $t$ test was also performed between the right and left foot groups for each clinical parameter, with a $5 \%$ significance level.

\section{Results}

\section{Postmortem Cadaver CT Scans}

All cadaveric specimens had foot deformities: valgus in 2), flat feet in 2, high arched foot in 1, and varus in 1 . Furthermore, 1 of the feet had hallux valgus deformities and another had hallux rigidus. 
Table 1

Descriptive parameters used to represent the main features of each bone

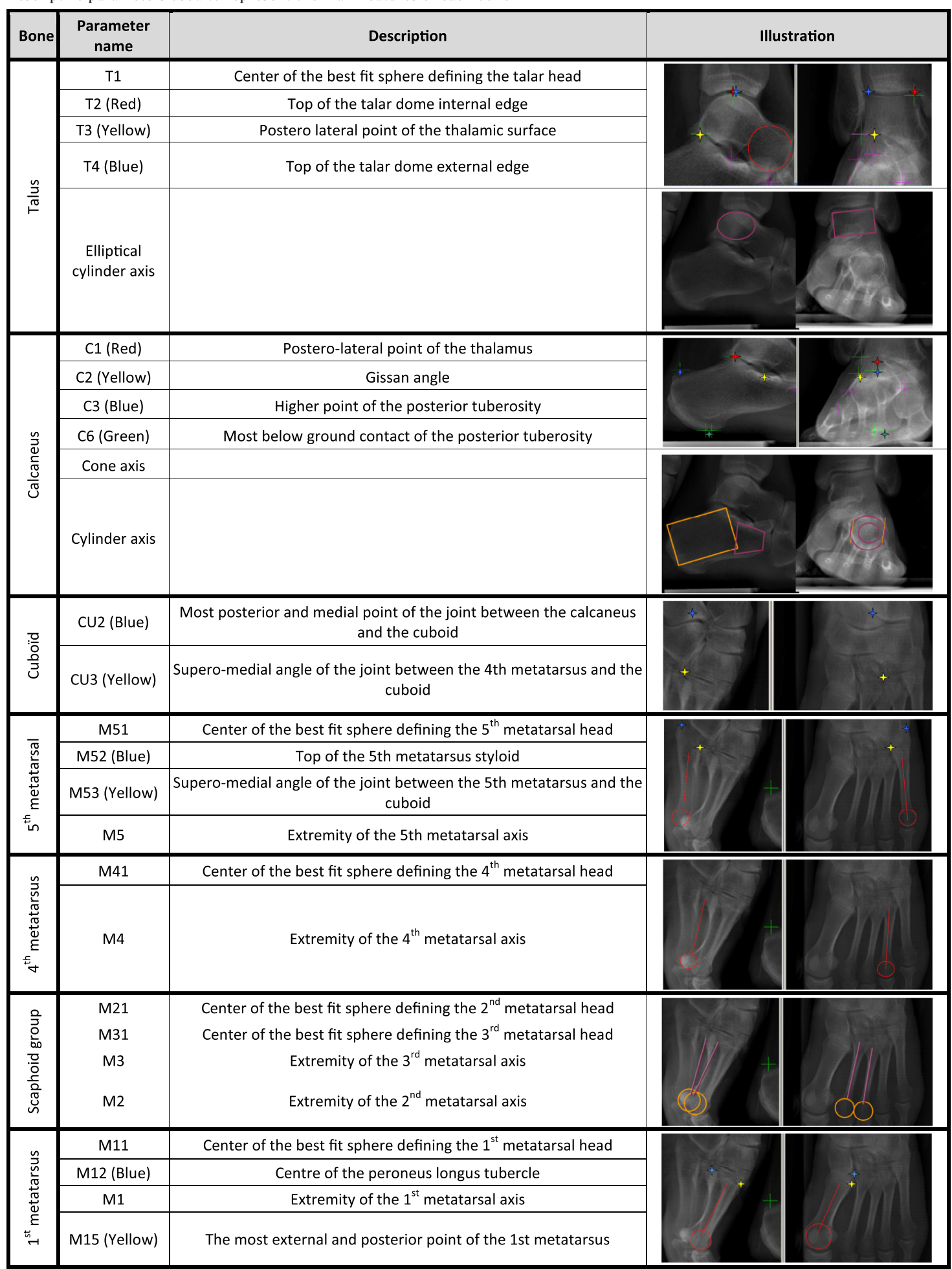

\section{Accuracy Assessment}

The average, RMS error, and maximum error (point-to-surface distance) of the proposed 3D reconstruction method of the foot from the biplanar x-ray images for the 6 cadaveric feet have been summarized in Table 3. The results showed a mean difference of $1.0 \mathrm{~mm}$, with a 2 RMS of $2.8 \mathrm{~mm}$.
Reliability of Anatomic Landmarks

The 95\% CIs computed for the descriptive parameters used to define the 3D SPPM of the foot have been summarized in Table 4. Most of the length parameters had a $95 \% \mathrm{CI}$ of $<2.0 \mathrm{~mm}$, and most of the angle parameters had a $95 \% \mathrm{CI}<2.0^{\circ}$. The intraobserver reliability was $<1.0 \mathrm{~mm}$ for the points and $<2.0^{\circ}$ for the axis angles. 
Table 2

Clinical parameters computed from simplified personalized parametric model: 3-dimensional angles and 2-dimensional projected angles on both anteroposterior and lateral views

\begin{tabular}{|c|c|}
\hline Clinical Parameter & Description \\
\hline \multicolumn{2}{|l|}{ AP view } \\
\hline First to second metatarsal angle & $\begin{array}{l}\text { Angle between first and second metatarsal } \\
\text { axes }\end{array}$ \\
\hline Talocalcaneal divergence & Projection of talocalcaneal 3D angle \\
\hline $\begin{array}{l}\text { Anteroposterior talus-first metatarsal } \\
\text { angle }\end{array}$ & $\begin{array}{l}\text { Projection of angle between talar axis and } \\
\text { first metatarsal axis (abduction- } \\
\text { adduction, talus-first metatarsal) }\end{array}$ \\
\hline $\begin{array}{l}\text { First-fifth metatarsal angle (foot } \\
\text { spreading) }\end{array}$ & Projection of first-fifth metatarsal angle \\
\hline Calcaneus-fifth metatarsal angle & $\begin{array}{l}\text { Projection of angle between calcaneus axis } \\
\text { and fifth metatarsal axis (abduction- } \\
\text { adduction, calcaneum-fifth metatarsal) }\end{array}$ \\
\hline \multicolumn{2}{|l|}{ Lateral view } \\
\hline Talocalcaneal divergence & Projection of talocalcaneal 3D angle \\
\hline Meary's angle & $\begin{array}{l}\text { Projection of angle between talar axis and } \\
\text { first metatarsal axis }\end{array}$ \\
\hline Lateral first-fifth metatarsal angle & $\begin{array}{l}\text { Sagittal projection of first-fifth metatarsal } \\
\text { angle: supination angle of forefoot }\end{array}$ \\
\hline \multicolumn{2}{|l|}{ 3D view } \\
\hline Talus-first metatarsal angle & $\begin{array}{l}\text { Angle between talar axis and first } \\
\text { metatarsal axis }\end{array}$ \\
\hline 3D talocalcaneal angle & Angle between talus and calcaneal axis \\
\hline First-fifth metatarsal 3D angle & $\begin{array}{l}\text { Spread footing angle (angle between first } \\
\text { and the fifth metatarsal axis) }\end{array}$ \\
\hline Foot twisting angle & $\begin{array}{l}\text { Angle between } 2 \text { planes: sagittal plane of } \\
\text { calcaneus and plane involving first and } \\
\text { fifth metatarsal axes }\end{array}$ \\
\hline
\end{tabular}

Abbreviations: AP, anteroposterior; 3D, 3-dimensional.

\section{Baseline Data}

All clinical parameters, computed from the 3D reconstruction of the 17 subjects ( 34 feet), followed a normal distribution. The mean \pm standard deviation and range are reported in Table 5 . The most variable parameters were the talocalcaneal divergence, AP talus-first metatarsal angle, M1 talus 3D angle, and foot twisting angle. The results showed that no statistically significant difference was present between the clinical parameters of the left and right feet.
Table 3

Point-to-surface distance between computed tomographic scan reconstruction and 3-dimensional stereoradiographic reconstruction: mean error, 2 root mean square error, and maximum error

\begin{tabular}{llll}
\hline Bone & $\begin{array}{l}\text { Mean Distance } \\
(\mathrm{mm})\end{array}$ & $\begin{array}{l}\text { 2 RMS Error } \\
(\mathrm{mm})\end{array}$ & $\begin{array}{l}\text { Maximum Distance } \\
(\mathrm{mm})\end{array}$ \\
\hline Talus & 1.4 & 3,7 & 6,2 \\
Calcaneus & 1.4 & 3,8 & 6,7 \\
Navicular group & 0.9 & 2,4 & 5,9 \\
First metatarsal bone & 0.8 & 2,3 & 4,3 \\
Fourth metatarsal bone & 0.8 & 2,5 & 3,8 \\
Fifth metatarsal bone & 0.6 & 1,8 & 3,6 \\
Cuboid & 1.2 & 3,2 & 5,3 \\
Average over whole foot & 1.0 & 2,8 & 5,1 \\
\hline
\end{tabular}

Abbreviation: RMS, root mean square.

\section{Discussion}

3D model-based reconstruction techniques using 2D calibrated lowdose biplanar X-ray images are a promising alternative to the standard medical imaging procedures and have been proved to be reliable for assessing the clinical parameters of the spine (15), rib cage (16-18), upper limb (19), lower limb $(4,20)$, and external envelope (21). The assessment of the clinical indexes of the foot and ankle from biplanar $\mathrm{x}$-ray images, however, are more complicated because of the superposition of all the bones in the frontal plane. The radiographic acquisition protocol proposed in the present study allows one to overcome this major bottleneck. Thus, a new method for the 3D reconstruction of the foot and ankle in the weightbearing position from low-dose biplanar radiographs with clinical measurement assessment for clinical routine practice has been proposed and validated in the present study.

Many of the anatomic landmarks used to define the 3D SPPM of the foot are reproducible, allowing for the correct assessment of clinical indexes. This is essential for the proper initial evaluation and planning of therapy for patients with foot or ankle abnormalities or deformities. Because foot pathologies often involve components of deformation in the 3 spatial planes (3,26,27), 3D modeling will be of value to achieve accurate analysis of foot deformities.

The lateral and AP projections of the talocalcaneal divergence angles reported in the present study are consistent with the reported data

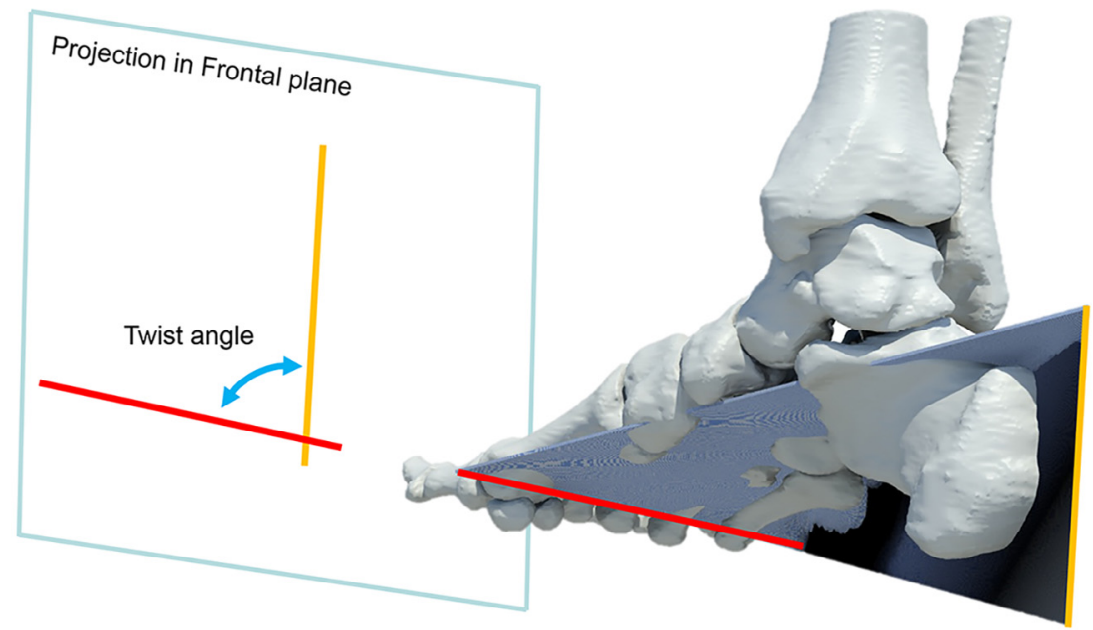

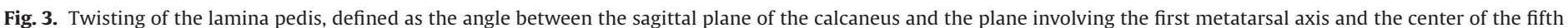
metatarsal head. The angle measurement in the frontal plane is also shown. 
Table 4

Ninety-five percent confidence intervals computed for descriptive parameters used to define 3-dimensional simplified personalized parametric model of the foot

\begin{tabular}{|c|c|c|c|c|c|}
\hline \multirow[t]{2}{*}{ Bone } & \multirow[t]{2}{*}{ Descriptive Parameter } & \multicolumn{4}{|c|}{ 95\% Confidence Interval } \\
\hline & & $\begin{array}{l}\mathrm{X} \text {-Component } \\
(\mathrm{mm})\end{array}$ & $\begin{array}{l}\text { y-Component } \\
(\mathrm{mm})\end{array}$ & $\begin{array}{l}\text { z-Component } \\
(\mathrm{mm})\end{array}$ & $\begin{array}{l}\text { Angle } \\
\left({ }^{\circ}\right)\end{array}$ \\
\hline \multirow[t]{5}{*}{ Talus } & $\mathrm{T} 1$ & $0.7^{*}$ & $1.8^{*}$ & $1.1^{*}$ & \\
\hline & $\mathrm{T} 2$ & 2.4 & $0.7^{*}$ & $0.3^{*}$ & \\
\hline & T3 & 2.5 & 2.5 & $0.6^{*}$ & \\
\hline & $\mathrm{T} 4$ & 3.0 & $1.2^{*}$ & $0.6^{*}$ & \\
\hline & Elliptical cylinder axis & & & & 3.8 \\
\hline \multirow[t]{6}{*}{ Calcaneus } & $\mathrm{C} 1$ & 2.3 & 2.7 & $0.8^{*}$ & \\
\hline & $\mathrm{C} 2$ & $1.1^{*}$ & $0.9^{*}$ & $1.9^{*}$ & \\
\hline & $\mathrm{C} 3$ & $0.9^{*}$ & $0.9^{*}$ & $0.9^{*}$ & \\
\hline & C6 & $2.0^{*}$ & $1.8^{*}$ & $0.3^{*}$ & \\
\hline & Cone & & & & $1.3^{*}$ \\
\hline & Cylinder axis & & & & 2.6 \\
\hline \multirow[t]{4}{*}{ Scaphoid group } & M21 & $1.6^{*}$ & $1.0^{*}$ & $1.0^{*}$ & \\
\hline & M31 & $1.4^{*}$ & $0.9^{*}$ & $1.0^{*}$ & \\
\hline & M2 axis & & & & 3.7 \\
\hline & M3 axis & & & & 8.5 \\
\hline \multirow[t]{4}{*}{ M1 } & M11 & $1.0^{*}$ & $1.3^{*}$ & $1.4^{*}$ & \\
\hline & M12 & $0.6^{*}$ & $1.4^{*}$ & $0.7^{*}$ & \\
\hline & M15 & $1.1^{*}$ & $1.9^{*}$ & 3.4 & \\
\hline & M1 axis & & & & $1.1^{*}$ \\
\hline \multirow[t]{2}{*}{ M4 } & M41 & $1.6^{*}$ & $0.7^{*}$ & $0.8^{*}$ & \\
\hline & M4 axis & & & & $0.5^{*}$ \\
\hline \multirow[t]{4}{*}{ M5 } & M51 & $1.1^{*}$ & $1.2^{*}$ & $0.8^{*}$ & \\
\hline & M52 & $0.7^{*}$ & 2.0 & $0.6^{*}$ & \\
\hline & M53 & $1.2^{*}$ & 3.4 & $1.9^{*}$ & \\
\hline & M5 axis & & & & 3.0 \\
\hline \multirow[t]{2}{*}{ Cuboid } & CU2 & $1.6^{*}$ & $0.9^{*}$ & $0.8^{*}$ & \\
\hline & CU3 & 4.6 & $1.7^{*}$ & $0.9^{*}$ & \\
\hline
\end{tabular}

Abbreviations: CI, confidence interval; CU, cuboid; M, metatarsal; T, talus.

* Length parameter with $95 \% \mathrm{CI}$ of $<2.0 \mathrm{~mm}$ and angle parameter with $95 \% \mathrm{CI}<2.0^{\circ}$.

$(1,28)$. However, the average 3D talocalcaneal divergence measurements showed greater values at $52^{\circ} \pm 5.9^{\circ}$ (range $40.7^{\circ}$ to $64.6^{\circ}$ ) than the previously reported $2 \mathrm{D}$ data. This can be explained by the presence of projection biases in the $2 \mathrm{D}$ data. The $3 \mathrm{D}$ talocalcaneal divergence angles were greater than the 2D talocalcaneal divergence angles because they were computed from a 3D reconstruction in the plane of maximal angulation. These data suggest that the actual talocalcaneal divergence angle might be underestimated on lateral or AP views. This finding was correlated by Adamsbaum et al (29), who suggested that the actual AP talocalcaneal divergence cannot be evaluated using traditional radiographs for a vertical talus. It seems that

Table 5

Mean \pm standard deviation of clinical parameters computed from 3-dimensional reconstruction from 17 subjects ( 34 feet)

\begin{tabular}{lll}
\hline Clinical Parameter & $\begin{array}{l}\text { Mean } \pm \text { Standard } \\
\text { Deviation }\left({ }^{\circ}\right)\end{array}$ & Range $\left(^{\circ}\right)$ \\
\hline AP view & & \\
$\quad$ First-second metatarsal angle & $10.3 \pm 3.5$ & 2.3 to 15.4 \\
Talocalcaneal divergence & $27.7 \pm 9.6$ & 4.9 to 49.7 \\
Anteroposterior talus-first metatarsal angle & $10.8 \pm 8.3$ & 0.5 to 39.2 \\
First-fifth metatarsal angle (spread footing) & $28.6 \pm 3.5$ & 23.8 to 38.8 \\
Calcaneus-fifth metatarsal angle & $8.3 \pm 5.4$ & 0.7 to 22.3 \\
Lateral view & & 34.0 to 54.6 \\
Talocalcaneal divergence & $13.4 \pm 6.5$ & 2.7 to 27.3 \\
Meary's angle & $9.2 \pm 4.3$ & 0.0 to 16.6 \\
Lateral first-fifth metatarsal angle & & \\
3D view & $16.4 \pm 7.5$ & 5.5 to 39.9 \\
Talus-first metatarsal angle & $52.0 \pm 5.9$ & 40.7 to 64.6 \\
3D talocalcaneal angle & $29.1 \pm 3.2$ & 23.5 to 38.8 \\
First-fifth metatarsal 3D angle & $87.1 \pm 7.1$ & 73.8 to 104.0 \\
Foot twisting angle &
\end{tabular}

Abbreviations: AP, anteroposterior; 3D, 3-dimensional. the actual talocalcaneal divergence angle can only be evaluated after $3 \mathrm{D}$ reconstruction of the weightbearing foot. This 3D angle seems to be more informative and is also more interesting than its projection in the sagittal or horizontal plane.

In addition to the standard clinical measurements, we have proposed and evaluated the foot twisting angle (defined as the angle between the sagittal plane of the calcaneus and the plane involving the first and fifth metatarsal axis), which is a parameter of main interest. It illustrates the global architecture of the calcaneopedal unit (26) and has been described under the name lamina pedis (30). However, to the best of our knowledge, it has not been quantified. This angle involves a $3 \mathrm{D}$ vision of the weightbearing foot and cannot be assessed clinically or using conventional radiographs. Theoretically, this angle will be increased in the cavovarus foot (31) and decreased in the flat foot (3). Our results have shown that this angle is reproducible. Future studies are needed of pathologic feet to quantify the variations in this angle.

The evaluation of the talo-first metatarsal angle in the horizontal plane gives global information about foot adduction or abduction $(3,26)$. However, it does not provide specific information, because this adduction can be located at different levels: subtalar, midtarsal, or tarsometatarsal joints, with or without bony deformities. The talofirst metatarsal angle in the sagittal plane (Meary's angle) allows one to quantify the cavus or planus of the medial arch (1). Our findings concerning Meary's angle (average $13.4^{\circ} \pm 6.5^{\circ}$ ) are consistent with previously reported values $(1,27)$. The information obtained in both the lateral and AP planes was complementary. In the future, it would be useful to apprehend this angle in 3 dimensions for correct assessment of the mid-forefoot orientation compared with the hindfoot orientation, which are combined in cavovarus and planus feet in 2D approaches $(3,31)$. Similarly, it would be interesting to appreciate the 3D orientation of the first-fifth metatarsal angle, which is indicative 
of forefoot pronation-supination (1). The average calcaneal pitch angle was $10.6^{\circ} \pm 4.3^{\circ}$ in the weightbearing foot, consistent with data measured on conventional radiographs $(1,28)$.

All the other 2D projected angles were consistent with the reported data (1), including the first-second metatarsal angle, AP talusfirst metatarsal angle, first-fifth metatarsal angle, AP calcaneusfifth metatarsal angle, and lateral first-fifth metatarsal angle.

The proposed method does have some limitations. If the manual landmark digitization process requires $<10$ minutes and allows for calculation of all the 3D parameters, the manual adjustment phase to realize the 3D morpho-realistic model is still long. After this proof of concept, the use of statistical parametric models and image processing should yield time reductions, as was performed for other anatomic structures (32). This will provide an efficient method of reconstruction that can be used both in clinical routine practice and for subjectspecific biomechanical models. Another limitation of the method is that only asymptomatic adults were considered. The method and baseline data require adaptation to young children, for which the lack of ossification is an issue, and for pathologic feet with large deformations. In both cases, landmark detection could be difficult. Moreover, in the present study, the 3D tibial and fibular parameters were not investigated, because we focused on the foot. Further studies of the lower limb and, in particular, the tibia should increase the global understanding of the foot configuration in the weightbearing position. The position of the foot has been studied in comparison with the position of the talus, and it would be interesting to study its position relative to the talotibiofibular unit (26). Despite these limitations, to the best of our knowledge, the present study is the first to propose an accurate 3D method for reconstruction of the foot. A future perspective will be to analyze the alignment of the pelvis, lower limb, and foot morphology using on the database acquired in the present study. These results also open the way for the fast development of personalized finite element models of the foot and ankle to assist surgeons in treatment planning.

\section{Acknowledgments}

The authors thank the ParisTech BiomecAM chair program on subject-specific musculoskeletal modeling, and in particular COVEA and Société Générale. The authors also thank Audrey Arts, Roxane Huet, and Thomas Joubert for their kind technical assistance.

\section{References}

1. Davids JR, Gibson TW, Pugh LI. Quantitative segmental analysis of weight-bearing radiographs of the foot and ankle for children: normal alignment. J Pediatr Orthop 25:769-776, 2005

2. Rungprai C, Goetz JE, Arunakul M, Gao Y, Femino JE, Amendola A, Phisitkul P. Validation and reproducibility of a biplanar imaging system versus conventional radiography of foot and ankle radiographic parameters. Foot Ankle Int 35:11661175, 2014.

3. Bourdet C, Seringe R, Adamsbaum C, Glorion C, Wicart P. Flatfoot in children and adolescents: analysis of imaging findings and therapeutic implications. Orthop Traumatol Surg Res 99:80-87, 2013.

4. Chaibi Y, Cresson T, Aubert B, Hausselle J, Neyret P, Hauger O, de Guise JA, Skalli $W$. Fast 3D reconstruction of the lower limb using a parametric model and statistical inferences and clinical measurements calculation from biplanar X-rays. Comput Methods Biomech Biomed Engin 15:457-466, 2012.

5. Sutter R, Pfirrmann CWA, Espinosa N, Buck FM. Three-dimensional hindfoot alignment measurements based on biplanar radiographs: comparison with standard radiographic measurements. Skeletal Radiol 42:493-498, 2013.

6. Colin F, Horn Lang T, Zwicky L, Hintermann B, Knupp M. Subtalar joint configuration on weightbearing CT scan. Foot Ankle Int 35:1057-1062, 2014.

7. Johnson PT, Fayad LM, Frassica FJ, Fishman EK. Computed tomography of the bones of the foot: neoplastic disease. J Comput Assist Tomogr 33:436-443, 2009.

8. Wong GNL, Tan TJ. MR imaging as a problem solving tool in posterior ankle pain: a review. Eur J Radiol 85:2238-2256, 2016.

9. Tuominen EKJ, Kankare J, Koskinen SK, Mattila KT. Weight-bearing CT imaging of the lower extremity. AJR Am J Roentgenol 200:146-148, 2013.

10. Wan Z, Malik A, Jaramaz B, Chao L, Dorr LD. Imaging and navigation measurement of acetabular component position in THA. Clin Orthop 467:32-42, 2009.

11. Richter M, Seidl B, Zech S, Hahn S. PedCAT for 3D-imaging in standing position allows for more accurate bone position (angle) measurement than radiographs or CT. Foot Ankle Surg 20:201-207, 2014

12. Coughlin MJ, Grimes JS, Traughber PD, Jones CP. Comparison of radiographs and CT scans in the prospective evaluation of the fusion of hindfoot arthrodesis. Foot Ankle Int 27:780-787, 2006.

13. Dubousset J, Charpak G, Dorion I, Skalli W, Lavaste F, Deguise J, Kalifa G, Ferey S. A new 2D and 3D imaging approach to musculoskeletal physiology and pathology with low-dose radiation and the standing position: the EOS system. Bull Acad Natl Med 189:287-297, 2005

14. Skalli W, Mitton D, de Guise J, Dubousset J. The EOS system: new perspectives for musculoskeletal biomechanics. J Biomech 39:S460, 2006.

15. Humbert L, De Guise JA, Aubert B, Godbout B, Skalli W. 3D reconstruction of the spine from biplanar X-rays using parametric models based on transversal and longitudinal inferences. Med Eng Phys 31:681-687, 2009.

16. Aubert B, Vergari C, Ilharreborde B, Courvoisier A, Skalli W. 3D reconstruction of rib cage geometry from biplanar radiographs using a statistical parametric model approach. Comput Methods Biomech Biomed Eng Imaging Vis 4:281-295, 2016.

17. Jolivet E, Sandoz B, Laporte S, Mitton D, Skalli W. Fast 3D reconstruction of the rib cage from biplanar radiographs. Med Biol Eng Comput 48:821-828, 2010.

18. Mitton D, Zhao K, Bertrand S, Zhao C, Laporte S, Yang C, An KN, Skalli W. 3D reconstruction of the ribs from lateral and frontal X-rays in comparison to $3 \mathrm{D}$ CT-scan reconstruction. J Biomech 41:706-710, 2008.

19. Lebailly F, Lima LVPC, Clairemidi A, Aubert B, Guerard S, Chaibi Y, de Guise J, Fontaine C, Skalli W. Semi-automated stereoradiographic upper limb 3D reconstructions using a combined parametric and statistical model: a preliminary study. Surg Radiol Anat 34:757-765, 2011

20. Quijano S, Serrurier A, Aubert B, Laporte S, Thoreux P, Skalli W. Three-dimensional reconstruction of the lower limb from biplanar calibrated radiographs. Med Eng Phys 35:1703-1712, 2013.

21. Nérot A, Choisne J, Amabile C, Travert C, Pillet H, Wang X, Skalli W. A 3D reconstruction method of the body envelope from biplanar X-rays: evaluation of its accuracy and reliability. J Biomech 48:4322-4326, 2015.

22. MacConnail M, Basmajian J. Muscles and Movements: A Basis for Human Kinesiology, Williams \& Wilkins, Baltimore, 1969.

23. Cuno A, Esperança C, Oliveira A, Cavalcanti PR. 3D as-rigid-as-possible deformations using MLS. Proc 27th Comput Graph Int Conf 115-122, 2007.

24. Trochu F. A contouring program based on dual kriging interpolation. Eng Comput 9:160-177, 1993

25. Thomas JL, Kunkel MW, Lopez R, Sparks D. Radiographic values of the adult foot in a standardized population. J Foot Ankle Surg 45:3-12, 2006.

26. Seringe R, Wicart P; French Society of Pediatric Orthopaedics. The talonavicular and subtalar joints: the "calcaneopedal unit" concept. Orthop Traumatol Surg Res 99:S345-S355, 2013.

27. Vanderwilde R, Staheli LT, Chew DE, Malagon V. Measurements on radiographs of the foot in normal infants and children. J Bone Joint Surg Am 70:407-415, 1988.

28. Gentili A, Masih S, Yao L, Seeger LL. Pictorial review: foot axes and angles. Br J Radiol 69:968-974, 1996.

29. Adamsbaum C, Seringe R, Kalifa G. Réalité de la divergence astragalo-calcanéenne de face dans le pied convexe congénital. Rev Imag Médicale 3:591-592, 1991.

30. Walls WKJ. Muscles and movements: a basis for human kinesiology. J Anat 108:200, 1971.

31. Wicart P. Cavus foot, from neonates to adolescents. Orthop Traumatol Surg Res 98:813-828, 2012.

32. Pomero V, Mitton D, Laporte S, de Guise JA, Skalli W. Fast accurate stereoradiographic 3D-reconstruction of the spine using a combined geometric and statistic model. Clin Biomech (Bristol, Avon) 19:240-247, 2004. 